\title{
Biofthics of Life Programs: Taking Seriously Moral Pluralism in Clinical SetTings
}

\author{
L. Niebroj \\ Department of Philosophy and Pedagogy, Medical University of Silesia, Katowice, Poland
}

\begin{abstract}
Background: In the more and more globalized world, the experience of moral pluralism (often related to, or based upon, religious pluralism) has become a common issue which ethical importance is undeniable. Potential conflicts between patients' and therapeutic teams' moral views and between moral beliefs of the particular member of this team are being resolved in the light of bioethical theories, among which principlism remains the mainstream approach to biomedical ethics. The question arises, however, whether this approach, in itself, as being strictly bound to the specific and distinct American philosophical tradition, is to be considered the tool for so called 'moral imperialism'. Also architectures of principlism, in particular by elaborating the concept of common morality, defend the applicability of their theory to the pluralistic settings, it should be emphasized that the idea that some norms and standards of moral character are shared by all morally serious people in every culture has attracted criticism both from empirical as well as theoretical backgrounds.

Objective: This paper aims at reconsidering principlism so that it would be more suitable for resolving moral dilemma in ethically pluralistic clinical settings.

Methods: Lakatos' sophisticated methodological falsification is used into two different ways: (1) to construct a concept of 'life programs' and (2) to confront a newly elaborated ethical theory with principlism. The reflection is limited to the norms related to the key issue in clinical ethics, i.e., respecting the patient's autonomy.

Results: The concepts of common morality and particular moralities are interpreted (in the light of Lakatos' philosophy of sciences) as 'hard core' and 'protective belt' of life programs, respectively. Accepting diversity of research programs, Lakatos maintains the idea of the objectivity of truth. Analogously, the plurality of life programs does not put into question the objectivity of moral values. The plurality of moral norms not only respects the objectivity of the good, but also can be seen as a condition sine qua non of such objectivity in the changing socio-historical context of doctor-patient relationship.

Conclusions: The life program approach to bioethics and clinical ethics in particular, can be seen as a form of widening of principlism. This new approach, being non-relativistic, is at the same time sensitive to moral pluralism experienced in everyday medical practice.
\end{abstract}

Key words: principlism, common morality, pluralism, life programs bioethics

\section{INTRODUCTION}

When remembering the early years of bioethics, Arthur Caplan admits: "bioethics sounded very American. Bioethics has talked with an American accent for a long time. It's only starting to change now" [1, p. 89]. This opinion, probably, does not pose any special concerns when it is considered from the strictly 'historical' perspective. Though 'bioethics' can be understood in different ways [2], it is most commonly conceived as an academic discipline originated in the U.S. in the 1960s and 1970s [3]. The real problem arises when interpreting Caplan's opinion in much broader sense: bioethics not only got started in America, but also (or better to say: first and foremost) has been structured to reflect the values, logic of reasoning, and moral practices accepted in the bioethics' socio-cultural 'place' of origin [4].

What can be said about bioethics as such becomes particularly obvious when focusing on the mainstream of bioethical reflection. The four principles approach to biomedical ethics, increasingly known as principlism, from the first edition of the landmark book by Beauchamp and Childress Principles of Biomedical Ethics, is accused of reflecting relatively narrow cultural tradition but aspiring to be globally applicable. Critics point out that it would be an exaggeration to describe principlism as based on Western philosophical tradition [5]. They insist instead that its intellectual background is in fact limited only to the specific and narrow stream of philosophical thought of this tradition. Despite such limitations, Beauchamp and Childress are definite about the universal validity of moral principles that govern the realm of biomedical ethics. They find justification of their claim in the concept of common morality [6]. The concept, as they perceive it, which permits to overcome essential problems related to the cultural, religious, and moral pluralism of the contemporary societies.

Writing about 'pluralism of the contemporary societies' instead of 'perpetual pluralism of human societies' finds its reasons in the fact that, mostly due to the process of globalization, the awareness of the cultural diversity has increased rapidly just in the last decades and, moreover, the mode of experiencing pluralism has underwent profound changes. Some time 
ago, the cultural, religious and/or moral diversities had been observed between groups of people living in different places, i.e., in different geographical places, but also in different (in the sense 'sharply divided') sociocultural niches. Nowadays, pluralism of beliefs is present almost in every place. Quiet lately, pluralism has been the issue debated in bioethics exclusively within the context of multicenter and international research projects; presently this issue is inherent in daily practice of medicine [7]. Lie has accepted, as an overarching principle of her reflections in teaching cultural competency to medical students, that "every patientdoctor encounter is a cross-cultural encounter" $[8, \mathrm{p}$. 486]. The author admits that this cross-cultural character can be based on differences which are presented explicitly or implicitly in the patient-doctor relationship. Among such differences, there is a wide range of issues, starting from ethnicity, religious values, sex, sexual orientation, but not forgetting age, socioeconomic status, and disability. It should not be forgotten that the cultural and consequently moral pluralism affects not only doctor-patient relationship, but it also can influence the relationship within a therapeutic team. Doctors, nurses, and other members of these teams are the moral agents who do not necessarily share the same set of moral (cultural, religious etc.) beliefs [9].

An increase in social awareness of the cultural diversity, on the one hand, and the fact that the issue of pluralism is presented in everyday practice in clinical settings, on the other, permits to hold a view that the problems related to the cultural diversity should be regarded as the most important challenges faced by the contemporary bioethics. At the same time, however, there are reasonable doubts whether classical principlism is taking the problem of pluralism seriously enough. The main aim of this paper is to present a new approach to biomedical ethic, called 'life programs bioethics' [10]. This new approach is considered to be a form of the development/widening of principlism, which does not lose the undeniable values of its predecessor, but which is more sensitive to the problem of pluralism and can save bioethics from the accusation of being a kind of moral imperialism. The term 'moral imperialism' is broadly defined as an attempt to impose moral standards accepted in the one particular culture (usually developed in the bigger and richer, in economical terms, countries) onto other cultures [11].

\section{Methods}

Methodology of scientific research programs and sophisticated methodological falsification as a way to confront different research programs are accepted in this study and then elaborated to accommodate them to the realm of bioethics. The structure of the life programs is shaped analogously to the Lakatos' research programs [12]. Three conditions of sophisticated methodological falsification (also slightly changed both in their wording and order) are used to compare the life programs approach to bioethics with the classical principlism. It is assumed that the new, proposed herein approach disproves that elaborated by Beauchamp and Childress if, and only if:
- the concept of life programs explains the previous success of principlism, i.e., all the non-refuted content of it is contained within the conception presented here;

- the concept of life programs exceeds the content of principlism, i.e., it predicts novel 'facts', i.e., 'facts' improbable in the light of, or even forbidden by, the older concept; and

- some of the excess content of the concept of life programs is corroborated when dealing with the practical problems of bioethics.

It is to be emphasized that the reflection on the last of the above outlined conditions is purposely limited in this paper to the issues related to the principle of respect for autonomy.

\section{RESUlTS AND DisCUSSION}

Although there are three conceptions in the four principle approach to bioethics which are to be taken into consideration when dealing with the problem of moral pluralism/moral diversity, i.e., (i) objective(s) of morality, (ii) common morality, and (iii) particular moralities, the concept of common morality seems to play the crucial role. Beauchamp defines the objectives of morality as the promotion of human flourishing "by counteracting conditions that cause the quality of people's lives to worsen" [13, p. 260]. Even if in the newest $\left(6^{\text {th }}\right)$ edition of Principles of Biomedical Ethics 'common morality' is defined without making a reference to 'objectives of morality', this definition needs to be explained in the light of a clear understanding of this concept. Beauchamp and Childress state that "the common morality is a set of norms shared by all person committed to morality" [6, p. 3].

To be committed to morality does not necessarily mean to realize the objectives of morality, but it is probably enough to be aware of them, and to be able to recognize properly the moral values. The common morality consists of standards of action, i.e., ethical obligations, both orders and prohibitions, and of standards of moral character traits (virtues). It should be emphasised that standards of action are: (i) very general in their character and in the consequence content-thin, (ii) universally shared by all people in all places, and consequently it is justified to judge all human conduct by its norms, and (iii) there are relatively stable. Although the concept of the common mortality has got historical character and is subject to possible changes over the time, in fact Beauchamp and Childress do not provide any example of such a change. It is worth noting that the architects of principlism state that standards of common morality are not actually the subject of investigations, these standards are rather assumed, not subject to discussion, in a scientific reflection on morality. Particular (or customary/professional) moralities - in contrast to the common morality - consist of standards which are (i) specific (content-rich), (ii) applicable to specific groups only, and (iii) are subjected to changes which occur frequently, can be profound, and, generally speaking, are welcome, as being considered to be warranted and praiseworthy. Due to these alterations, spe- 
cific norms are adjusted to the constantly changing world.

When arguing against the concept of common morality, Leith Turner notices that proponents of this concept do not provide any persuasive argument for support their claim that there are cross-cultural and practically ahistorical moral standards [5]. Moreover Turner states that there is rich and trustworthy evidence to sustain the opposite. According to the data obtained in empirical social studies across cultures and through time, there is an essential diversity of opinion about what is moral, and even what actually morality is. Such diversity of opinions manifests itself particularly clearly within the ethical issues related to the principle of the respect for autonomy (e.g., the problem of disclosure of information/truth telling) [14]. It is worth noticing, however, that Turner admits that within a given culture, and American culture can serve as a clear example of it, there are some beliefs which enjoy particular position and stability. In other words, using the concept of common morality, Beauchamp and Childress describe not cross-cultural moral standards, but particularly highly valuated norms which constitute the 'core' of morality within this, i.e., their own, American culture.

If the concepts accepted and, at least partially, elaborated by Beauchamp and Childress would be understood as terms which help to describe the very structure of moral beliefs as experienced just in one culture, it seems interesting to draw an analogy between the morality and scientific research programmes as described by Lakatos [12]. He recognizes that there are two essential elements which constitute any scientific research program, called by him: 'hard core' and 'protective belt'. The former consists in ideas shielded from falsification; do not open for any further negotiation. In contrast, the protective belt of an auxiliary hypothesis is permanently open for change, which aims at upholding the hard core's ideas in the face of anomalies experienced in the domains of a study. Lakatos admits that science could be considered as the most respectable kind of knowledge and that one of the man's most peculiar characteristics is just the respect for knowledge, as a consequence it is recognized that research programs are to be understood as most respectable ways to knowledge. Moreover, taking into account Lakatos' adherence to the realistic conception of truth, research programs could be seen as programs which are truth-oriented (objective truth-oriented). What seems to be of particular interest here in terms of 'pluralism' is the fact that Lakatos is not only aware of, but also accepts, coexistence of the different scientific research programs. Moreover, he provides criterion of rational choice between scientific programs. The progressive programs, which open new perspectives in research, should be chosen, while degenerative programs, which are able only to interpret facts just known should be rejected or rather 'put back on the shelf' according to the standards of postponed rationality.

The life programs approach to bioethics can be considered as a construct built form the elements of the Beauchamp and Childress reflection which are reconsidered and structured analogously to the Lakatos concept of scientific research programs [10]. Firstly, standards of action and character, recognized in the classical principlism as common morality (though within the context of life programs approach undoubtedly more precisely interpreted), are to be considered as an essential element of a given life program. They constitute its 'hard core'. It should be emphasized however that the hard core of life programs includes not only moral standards, but also some other, non-moral (e.g., ontological - the concept of human personhood [15], axiological - the value of suffering [16], etc.) beliefs. Secondly, norms which are open to discussion and change, and which in fact protect the stability of the hard core's standards, exactly these norms recognized as particular morality, are elements of the protective belt of a given life program. Thirdly, the analogy between scientific research programs and life program can be draw in regard to the objective of science and objective of morality. Lakatos undoubtedly is correct writing about the respect for knowledge (respect for the truth) as one of the most important characteristics of human nature. The question arises whether the respect for good is just such another man's characteristic. Life programs, analogously to research programs can be defined as being goodness-oriented (objective, or rather absolute goodness-oriented). Life programs, still analogously to the research programs, can be judged according to the rational criterion of progressivity/degenerativity. Postponed rationality indicates which programs should be promoted warning at the same time about the dangers of too hasty rejection of a program considered to be degenerative. The plurality of life programs represents not merely pluralism, but reasonable pluralism as described by John Rawls [17].

The most important novelty which the life program approach to bioethics introduces, when comparing with the classical principlism, is the assumption that the objectivity of moral values not only permits the existence of non-universal moral norms, but, in a certain sense, the diversity of norms is the necessary condition for making it possible to obtain moral good for people who belong to different cultures or moral traditions. Moreover, the life program approach to bioethics, which recognizes pluralism of moral opinions, justifies the introduction of, although limited, hierarchization of bioethical principles. The four principles of biomedical ethics, known from principlism, are divided into two pairs. One pair, i.e., the principle of respect for autonomy and the principle of justice, has the precedence over the second one, i.e., the principle of non-maleficence and the principle of beneficence, when it is necessary to resolve the moral problem 'between' life programs (or more precisely: when within bioethical problems the people are engaged who do not share the same life program). And vice versa, within a given life program, the principles of non-maleficence and beneficence should be considered as overweighing the two others. It is worth noticing that the complete lack of any hierarchization of principles known from the classical principlism is considered to be the main source of inevitable conflicts between duties related to the particular principles, especially between the principle of the 
respect for autonomy and the principle of beneficence.

Undoubtedly, the central ethical issue within the context of clinical bioethics is the moral rule which obliges doctors to obtain informed consent from their patients. This rule is considered to be strictly related to the principle of the respect for autonomy. The classical principlism seems to be unaware that within this approach to bioethics, the term autonomy assumes a specific, individualistic understanding. Whereas empirical and conceptual studies clearly show that in many a different culture, autonomy understood in this way obviously is not considered as the ideal of good life [18]. Turner observes that "there is a large body of literature that reveals how common it is within many ethnic groups for family members and physician to withhold information from dying relatives" [5, p. 202]. It is worth remembering here that disclosure of (material) information is listed as one of three essential information elements of informed consent [6]. Turner has no doubts that in some specific countries (such as Japan, Italy, China, and Ethiopia) moral standards accept nodisclosure of fatal information or even deceive (especially dying) patients [5]. Probably also in Poland informing the members of patients' family about very bad news, rather than the patients themselves, is not only a 'practical' standard, but it is also considered as the standard of ethically correct doctors' conduct. The Polish Code for Doctors' Ethics (Art. 17) directly authorizes withholding bad information, at least in some cases, from patients [19]. Empirical evidence corroborates the life program approach to bioethics' claim about the diversity of fundamental standards of action (i.e., these recognized to be elements of the life programs' hard cores), accepted in different cultures within the context of clinical medicine. On other hand, it should be emphasized that this claim should encourage undertaking scrupulous empirical inquires about morality [20].

The herein proposed, broad outline of the life programs approach to bioethics seems to disprove the classical principlism when taking into account the standards of methodological falsification. Firstly, in light of the new concept the previous successes of principlism are clearly explainable. In fact, all what is proposed by Beauchamp and Childress when they write about the common and customary morality can be seen as a particular, and - it should be added - a particularly influential (taking into account what role the American culture plays in the world) exemplification of the life program. Secondly, the life program approach to bioethics predicts novel facts which were not only improbable but directly forbidden by the classical principlism: diversity of moral norms ('hard core' or 'common morality' standards) within the context of a non-relativistic concept of ethics. Thirdly, diversity of moral convictions related to informed consent and information disclosure in particular [21, 22], permits to sustain that at least some of the rationales of the life program approach to bioethics are corroborated.

Conflicts of interest: No conflicts of interests were declared by the authors in relation to this article.

\section{REFERENCES}

1. Caplan A. Building stairs into slippery slopes. EMBO Reports $2005 ; 6(1): 8-12$.

2. Morioka M. When did „Bioethics” begin in each country? A proposal of a comparative study. Eubios J Asian Int Bioeth 2003; 13: 51-2.

3. Niebroj L. The origins of bioethics: Advances in resuscitation techniques. J Physiol Pharmacol 2008; 59 Suppl 6: 512-22.

4. Chattopadhyay S, De Vries R. Bioethics concerns are global, bioethics is Western. Eubios J Asian Int Bioeth 2008; 18(4): 106-9.

5. Turner L. Zones of consensus and zones of conflict: Questioning the 'Common Morality' presumption in bioethics. Kennedy Inst Ethics J 2003; 13(3): 193-218.

6. Beauchamp TL, Childress JF. Principles Of Biomedical Ethics. $6^{\text {th }}$ ed. New York: Oxford University Press 2009.

7. Marshall PA. Human rights, cultural pluralism, and international health research. Theor Med Bioeth 2005; 26(6): 529-57.

8. Lie D. A framework for enhancing and assessing cultural competency training. Kaohsiung J Med Sci 2009; 25: 48692.

9. Adams KE. Moral diversity among physicians and conscientious refusal of care in the provision of abortion services. J Am Med Womens Assoc 2003; 58(4): 223-6

10. Niebroj L. Bioetyka programów zyciowych. Rozwiniecie koncepcji pryncypializmu Beauchampa i Childressa. Katowice, SUM 2010 (Article in Polish).

11. Garrafa V, Lorenzo C. Moral imperialism and multi-centric clinical trials in peripheral countries. Cad Saude Publica 2008; 24(10): 2219-26.

12. Lakatos I. Falsification and the Methodology of Scientific Research Programmes. In: Criticism and the growth of knowledge. Lakatos I, Musgrave A (eds.) Cambridge, Cambridge University Press 1999, pp. 91-196.

13. Beauchamp TL. A defense of the common morality. Kennedy Inst Ethics J 2003; 13(3): 259-74.

14. Turner L. From the local to the global: Bioethics and the concept of culture. J Med Philos 2005; 30(3): 305-20.

15. Niebroj L, Jadamus-Niebroj D. Beyond purely ethical understanding of responsibility: A phenomenological approach. Ann Acad Med Stetin 2009; 55(1): 107-10.

16. Bargiel-Matusiewicz K, Krzyszkowska A. Dispositional optimism and coping with pain. Eur J Med Res 2009; 14 Suppl IV: 271-4.

17. Rawls J. Political Liberalism. $2^{\text {nd }}$ ed. New York, Columbia University Press, 2005.

18. Niebroj L, Olejniczak M, Kruzlak A. Kwestia autonomii w etyce medycznej: Filozofia Karola Wojtyly. Przegl Lek 2007; 64(12): 1045-8 (Article in Polish).

19. Kodeks Etyki Lekarskiej, available from: http://www.nil.org.pl/xml/nil/wladze/str_zl/zjazd7/ke, accessed 02/06/2010.

20. Alvarez AA. How rational should bioethics be? The value of empirical approaches. Bioethics 2001; 15(5-6): 501-19.

21. Jotkowitz A, Glick S, Gezundheit B. Truth-telling in a culturally diverse world. Cancer Invest 2006; 24(8): 786-9.

22. Oliffe J, Thorne S, Hislop TG, Armstrong EA. 'Truth telling' and cultural assumption in an era of informed consent. Fam Community Health 2007; 30(1): 5-15

Address for correspondence:

Leslaw Niebroj

Department of Philosophy \& Pedagogy,

Medical University of Silesia

12 Medykow St., 40-752 Katowice, Poland

Phone: +48322088628

E-mail: lniebroj@wp.pl 